\title{
Healthcare-associated infections in Intensive Care Units: epidemiology and infection control in low-to-middle income countries
}

\author{
Emine Alp ${ }^{1}$, Nizam Damani ${ }^{2}$ \\ ${ }^{1}$ Department of Infectious Diseases and Clinical Microbiology, Erciyes University, Faculty of Medicine, Kayseri, \\ Turkey \\ ${ }^{2}$ Craigavon Area Hospital, Portadown, Northern Ireland, United Kingdom
}

\begin{abstract}
Healthcare-associated infections (HAIs) are major patient safety problems in hospitals, especially in intensive care units (ICUs). Patients in ICUs are prone to HAIs due to reduced host defense mechanisms, low compliance with infection prevention and control (IPC) measures due to lack of education and training, and heavy workload and low staffing levels, leading to cross-transmission of microorganisms from patient to patient. Patients with HAIs have prolonged hospital stays, and have high morbidity and mortality, thus adding economic burden on the healthcare system. For various reasons, in low-to-middle income countries (LMICs), the scale of the problem is huge; each year, many people die from HAIs. In this review, epidemiology of HAIs and infection prevention and control measures in ICUs is discussed, with especial emphasis on LMICs. High rates of HAIs caused by multidrug-resistant organisms (MDROs) are serious problems in ICUs in LMICs. In view of increasing prevalence of MDROs, LMICs should establish effective IPC infrastructure, appoint IPC teams, and provide adequate training and resources. These resources to establish and appoint IPC teams can be released by avoiding ritualistic, wasteful, and unsafe IPC practices, and by diverting resources to implement basic IPC measures, including early detection of infection, isolation of patients, application of appropriate IPC precautions, adherence to hand hygiene, and implementation of HAIs care bundles and basic evidence-based practices.
\end{abstract}

Key words: infection control; low-to-middle income countries; healthcare-associated infections; intensive care units; multidrug resistant pathogens; nosocomial infections.

J Infect Dev Ctries 2015; 9(10):1040-1045. doi:10.3855/jidc.6832

(Received 03 March 2015 - Accepted 11 May 2015)

Copyright (C) 2015 Alp et al. This is an open-access article distributed under the Creative Commons Attribution License, which permits unrestricted use, distribution, and reproduction in any medium, provided the original work is properly cited.

\section{Introduction}

Healthcare-associated infections (HAIs) are serious patient safety problems in intensive care units (ICUs). Subsequently, a high proportion of these infections occurs in ICUs, with the rate exceeding $30 \%$ of all ICU admissions. ICU patients are prone to infection due to the reduced host defense mechanisms caused by the severity of illness, underlying diseases (diabetes, cancer, etc.), presence of multiple invasive devices resulting in disruption of anatomical and immunological protective barriers, and administration of various drugs. In addition, use of broad-spectrum antimicrobial agents has led to the emergence of multidrug-resistant organisms (MDROs).

On the other hand, due to heavy workload and low staffing levels, healthcare personnel working in ICUs have low compliance with hand hygiene and other basic infection prevention and control (IPC) measures, resulting in cross-infection of microorganisms from patient to patient [1]. For various reasons, in low-to- middle income countries (LMICs), the scale of the problem is huge; each year, more people die from HAIs than die from breast and prostate cancer, road traffic accidents, or war in these countries [2,3]. Due to high morbidity and mortality caused by these infections, early diagnosis and treatment of these infections with appropriate antibiotics is essential.

In this review, epidemiology of HAIs and infection prevention and control measures in ICUs are discussed, with special emphasis on LMICs. According to the World Bank Atlas method (2015), (http://data.worldbank.org/), low-income economies are defined as those with a gross national income (GNI) per capita of $\$ 1,045$ or less in 2013 ; middleincome economies are those with a GNI per capita of more than $\$ 1,045$ but less than $\$ 12,746$; and highincome economies are those with a GNI per capita of $\$ 12,746$ or more. Lower-middle-income and uppermiddle-income economies are separated at a GNI per capita of $\$ 4,125$. 


\section{Epidemiology of healthcare-associated infections in ICUs}

The European Prevalence of Infection in Intensive Care (EPIC) studies are some of the largest prevalence studies worldwide. In the EPIC-I study, which was conducted in 1992, ICUs from 17 countries in Western Europe participated. The overall rate of HAI was $45 \%$, and $21 \%$ of infections were acquired in the ICU. The greater incidence of infection and higher mortality rates were detected in South European countries, with the lowest incidence found in Switzerland (9\%-32\%). The possible reasons for these observed differences were explained by the differences in ICU capacity and staffing level, education and training in IPC, patient characteristics, and variations in the definition of surveillance used in these countries [4]. However, socioeconomic status might be another factor affecting ICU infections in these countries. The second EPIC study was conducted in 2007 and was re-named The Extended Prevalence of Infection in Intensive Care. In this study, 1,265 ICUs from 75 countries participated. On the day of the study, $51 \%$ of the patients were classified as infected, and these patients had higher mortality and longer length of stay in the ICU and hospital. Furthermore, in this international study, it was found that HAI rates were related to healthcare expenditure, with higher rates of infection reported in countries that had a lower proportion of gross domestic product (GDP) spent on healthcare [5]. On the other hand, the socioeconomic burden of HAIs is even more severe in LMICs. The International Nosocomial Infection Control Consortium (INICC) is the multinational research network established to control HAIs in hospitals within limited-resource countries. According to INICC results, ICU-acquired infection rates in developing countries were three- to fivefold higher than in hospitals in the United States of America (USA). Furthermore, the country's socioeconomic level and the type of hospital influenced HAI rates between LMICs [6].

On the other hand, antimicrobial resistance is a growing problem in ICUs all over the world [7]. ICUs in the USA and Europe reported that resistance of Gram-negative bacilli, specifically due to extendedspectrum beta-lactamases (ESBLs) and carbapenemresistant Enterobacteriaceae (CRE), are increasing in ICUs [8,9]. Infections caused by MDROs are more difficult to treat because options to treat these infections are limited; no new class of antibiotics against Gram-negative bacteria has been developed since the 1980s. As a result, infections caused by MDROs are not only difficult to treat but also very expensive, and are often more toxic than older agents. Infections caused by MDROs are often costly to treat and are often associated with much higher mortality $[1,5]$. The burden of HAIs with MDROs is much higher in ICUs in LMICs because of the failure to apply proper IPC measures and because of the lack of antibiotic stewardship programs [10,11]. Among other factors, the main reasons for increased antimicrobial resistance with MDROs are inappropriate use of antibiotics (especially broad-spectrum agents), lack of education and training in antibiotic prescribing, lack of availability of hand hygiene facilities and/or products and personal protective equipment (PPE), and presence of invasive devices. These factors contribute to failure to implement standard or contact IPC precautions $[1,12,13]$. In developing countries, due to limited resources, healthcare systems have very poor IPC infrastructure. Limited resources are combined with lack of awareness due to absence of basic surveillance, education and training, inappropriate use of antibiotics due to lack of a good microbiology diagnostic facility to diagnose infections in a timely manner and to provide local data on antibiotic resistance [13-15]. High rate of HAIs and inappropriate or lacking diagnostic facilities in developing countries encourage clinicians and ICU physicians to overuse antibiotics (especially broadspectrum antibiotics) to cover all possible pathogens. Many ICU clinicians prefer to use broad-spectrum and prolonged duration of antibiotics both for treatment and surgical antibiotic prophylaxis [13-16]. This practice has detrimental effects, as prolonged duration and inappropriate use, especially of broad-spectrum antibiotics, will lead to development not only of increased incidence of MDROs and increased incidence of antibiotic-associated infections, especially Clostridium difficile infections. In addition, indiscriminate use of broad-spectrum agents also causes secondary infections with yeast [1,13,17-19].

MDROs can successfully be controlled by early detection of carriers by active surveillance and prompt isolation of all suspected/confirmed cases with standard and contact IPC precautions on admission. However, implementation of this policy in LMICs is difficult and costly due to the lack of good diagnostic microbiology facilities, lack of surveillance of MDROs, lack of isolation facilities, and low availability of PPE and hand hygiene products [1]. 


\section{Infection control in low-to-middle income countries}

Challenges

The major challenges in LMICs are the lack of government regulations and guidance to implement effective IPC infrastructure, and lack of financial support to establish IPC programs. Many countries with limited resources either do not have IPC infrastructure or the IPC team and program in healthcare facilities are not effective due to lack of resources and availability of properly trained IPC personnel. As a result, even in some hospitals where IPC infrastructure is established, the guidelines adopted are those published by high-income countries, and are not applicable in LMIC settings. Due to lack of IPC infrastructure in most LMIC setting, information on HAIs surveillance is not available. In addition, information on burden of antibiotic resistance due to lack of good quality laboratory support is also lacking. As a result, it is not possible for IPC teams in local healthcare facilities to make a case that effective implementation of an ICP program to reduce HAIs is cost effective. In addition, the lack of availability of information about the local antibiotic susceptibility patterns results in clinicians prescribing broad-spectrum antibiotics, which are not only expensive but promote antibiotic resistance. If local antibiotic susceptibility information is available to the clinicians, then money can be saved through the prudent use of narrow-spectrum antibiotics, and the use of less expensive antibiotics can be implemented. Since these data are not available, the impact of these interventions to discharge patients early and release beds has not been fully assessed $[13,15,20]$.

In addition, preventing HCAs will improve patient safety and quality of care in healthcare facilities and help hospitals to prevent outbreaks.

An infection control team (ICT) consists of an infection control doctor (ICD) (which, depending on the country and resources, could be a hospital epidemiologist, infectious disease physician, or medical microbiologists) and infection control nurses (ICN). The ICT is mainly responsible for the day-today management of all IPC activities in the healthcare setting. It is recommended that a fully functioning and effectively communicating IPC team, including at least one full-time specifically trained infection control nurse with a ratio of 1:250 to $1: 100$ beds depending on the intensity and type of healthcare facility, an infection control doctor, and a professional skilled in data management is instituted at every healthcare facility. The IPC team will regularly monitor MDRO data and detect clusters/outbreaks and take appropriate actions [21]. However, in LMICs, due to the lack or late establishment of an official infection control program, infection control teams are inadequate, inexperienced, not well organized, and not well trained. In some hospitals, ICNs are not full-time equivalents and fulfill other responsibilities than infection control. IPC teams are therefore not always effective in preventing HAIs and not always successful in controlling cross-infection caused by MDORs [13,22].

Surveillance is the initial step towards reducing the risk of infection in ICUs. However, in developing countries, there is a lack of surveillance both at the local and national level. This is due to a lack of good quality laboratory support, and a lack of clear lines of communication both at the local and national level. Even these when these programs exist, there could be measurement errors regarding reporting of HAIs that can occur at the beginning of an IPC program [13,22].

The other leading problem in LMICs is overcrowding and heavy workload of healthcare personnel, who are the main determinants of compliance with IPC measures. Hugonnet et al. [23] demonstrated an association between a low nurse-topatient ratio and increased risk of HAIs and estimated that $30 \%$ of infections could be prevented with a ratio of $>2.2$ nurses to every patient. In LMICs, the numbers of healthcare workers are usually low; moreover, training of these personnel is often inadequate [13]. As a result, even when training is offered, it is difficult for clinical staff to attend due to low staffing levels in ICUs.

Hand hygiene is a simple and basic infection control measure [24]. However, adherence to the World Health Organization (WHO)'s Five Moments for Hand Hygiene is generally lower in ICUs than in other clinics due to the heavy workload [22]. In LMICs, infrastructure of ICUs (lack of sinks, water supply, difficult access to hygiene products, etc.), lack of training, behavioral aspects, poor nurse-to-patient ratio, and inappropriate use of gloves further reduce the compliance rates of hand hygiene in ICUs [13].

Inadequacy or lack of infection control products, hand disinfectants, PPE, and regular availability of clean water supply are important barriers for the implementation of effective IPC programs in developing countries. Another issue in these countries is unnecessary applications of and wasteful practices in infection control (routine environmental cultures, overuse of surface disinfectants, application of HEPA 
filters in ICUs, fumigation of rooms, use of sticky mat and overshoes, gowning for visitors, etc.), failure to properly separate and dispose of waste, misuse of PPEs (gloves, masks, shoe covers), or inappropriate and overuse of antibiotics. Gloves are sometimes used instead of hand hygiene, resulting in cross-infections, especially of MDROs, during patient care. Shoe covers are unnecessarily used to keep the hospitals floor clean. Lack of national guidelines and regulations lead to healthcare workers unfamiliar with IPC measures $[13,15]$.

Last but not least, a problem in LMICs is occupational exposure to pathogens including respiratory viruses, blood-borne pathogens, tuberculosis, and viral hemorrhagic fever. The majority of occupational infections have been reported from LMICs [25]. High prevalence of such pathogens in the community and lack of hospital IPC infrastructure and facilities (e.g., lack of isolation facilities, unavailability of infection control products, lack of PPE and hand hygiene products, lack of antimicrobials and immunization, reuse of single-use items, and heavy workload) constitute a severe risk for occupational exposure among healthcare workers. Organizational, administrative, and individual actions are necessary to reduce the risk of occupational exposure among HCWs $[13,15,26]$.

\section{Possible solutions}

LMICs should have proper regulation and guidance to help direct IPC programs on a country level. Establishment of national surveillance and reporting of reporting HAI rates in hospitals and MDORs at the country level is important to assess the magnitude of the problem. However, achieving these objectives is challenging, as it will require expert knowledge and resources, which can be difficult to implement because of the lack of awareness and lack of resources due to other competing priorities. However, after the recent outbreaks of highly contagious infectious diseases (e.g., Ebola and other viral hemorrhagic fever, swine influenza, and severe acute respiratory syndrome [SARS]) and the emergence of MDROs, especially CRE, politicians in various countries are now paying attention, as outbreaks can have a major economic impacts.

An IPC programs should be embedded as a part of every hospital's quality assurance programs. Welltrained ICN and ICD are necessary, so a standardized training program for ICN and ICD should be implemented nationwide. Though the ratio of infection control nurses to patient beds in LMICs has not been established, higher ratios are associated with better results, and the numbers should depend on the type of healthcare facility [27]. At the beginning of an IPC program, measures in infection control should be determined at the national level according to healthcare expenditure. Also, in the beginning, implementation of simple and cost-effective measures should be implemented. Educational and practical training should be provided to all clinics. Moreover, these activities will reduce the wasteful practices in infection control [15].

A training program is needed, but it alone is not enough. Implementation of multifaceted IPC programs and HAI care bundle strategy are needed for success in ICUs [21]. HAIs care bundles are packages of IPC measures based on evidence-based guidelines. A care bundle strategy is more effective than are single measures. However, selected care bundle elements should be simple, easy to implement, and inexpensive, and should be applicable to LMICs. Also, IPC teams should educate healthcare workers about care bundle elements, monitor compliance with bundle elements and the rates of HAIs (outcome) prior to implementing such programs. They should give feedback on compliance monitoring and on outcome surveillance data. The INICC showed successful reduction in device-associated infection rates with a multidimensional IPC approach in LMICs [28-30].

For the prevention of antibiotic-resistant bacteria, five strategies are recommended for healthcare settings: (i) implementation of IPC measures and isolation of patients to prevent cross-infection; (ii) early diagnosis of infection through surveillance and effective treatment of HAIs; (iii) prudent and rational usage of antimicrobials; (iv) education and training of clinical staff in IPC and appropriate use of antimicrobials agents; and (v) availability and monitoring of compliance with local antibiotic guidelines. The optimization of antibiotic usage for treatment and surgical prophylaxis (i.e., development of antibiotic stewardship programs in hospitals) is a principle of preventing resistance. This program can have different elements; additional efforts to improve education and training by implementing IPC guidelines and antibiotic prescription guidelines, surveillance, reporting local susceptibility data of microorganisms in timely manner, and using restricted antibiograms to avoid prescribing broad-spectrum antibiotics [1]. In ICU patients, initial antibiotic therapy usually covers most likely pathogens based on the local susceptibility data. This should be supplemented by antibiotic ward rounds by an ICU 
clinical microbiologist. However, clinicians should keep in mind that if that de-escalation therapy is initiated, once the microorganisms are identified, treatment must be changed to narrow-spectrum antibiotic therapy. In Turkey, prescribing broadspectrum parenteral antibiotics has been restricted to infectious disease specialists after 2004. Also, a nationwide antibiotic resistance surveillance system was established. Despite there being no randomized study showing the effectiveness of these regulations, there was a reduction of HAIs due to MRSA in ICUs in Turkey after these regulations were introduced [31].

\section{Conclusions}

High HAI rates with MDROs are serious problem in ICUs in LMICs. These infections are usually associated both with high morbidity and mortality. It is essential, in view of the increasing prevalence of MDROs, for LMICs to establish IPC infrastructure, appoint IPC teams, and provide adequate training and resources.

These resources can be made available by avoiding ritualistic and unsafe IPC practices and diverting resources and can enable the implementation of basic IPC measures including early detection and isolation of patients, application of standard and contact precautions, adherence to hand hygiene, implementation of HAI care bundles, establishment of IPC programs with practical training, and avoidance of wasteful practices.

\section{References}

1. Brusselaers N, Vogelaers D, Blot S (2011) The rising problem of antimicrobial resistance in the intensive care unit. Ann Inten Care 1: 47.

2. Lynch P, Pittet D, Borg MA, Mehtar S (2007) Infection control in countries with limited resources. J Hosp Infect 65: 148-150.

3. Allegranzi B, Bagheri Nejad S, Castillejos GG, Kilpatrick C, Kelley E, Mathai E (2011) Report on the Burden of Endemic Health Care-Associated Infection Worldwide. World Health Organisation. Available: http://apps.who.int/iris/bitstream/10665/80135/1/9789241501 507_eng.pdf. Accessed 15 September 2015

4. Vincent JL, Bihari D, Suter PM, Bruining HA, White J, Nicolas-Chanoin MH, Wolff M, Spencer RC, Hemmer M (1995) The prevalence of nosocomial infection in intensive care units in Europe: the results of the EPIC study. JAMA 274: 639-644.

5. Vincent JL, Rello J, Marshall J, Silva E, Antonio Anzueto A, Claude DM, Moreno R, Lipman J, Charles G, Sakr Y, Reinhart K (2009) International study of the prevalence and outcomes of infection in intensive care units. JAMA 302: 2323-2329.

6. Rosenthal VD, Maki DG, Graves N (2008) The International Nosocomial Infection Control Consortium (INICC): Goals and objectives, description of surveillance methods, and opertaional activities. Am J Infect Control 36: e1-e12.

7. Vincent JL (2013) Nosocomial infections in adult intensive care units. Lancet 361: 2068-2077.

8. Prabaker K, Weinstein RA (2011) Trends in antimicrobial resistance in intensive care units in the United States. Curr Opin Crit Care 17: 472-479.

9. van Duijn PJ, Dautzenberg MJD, Oostdijk EAN (2011) Recent trends in antibiotic resistance in European ICUs. Curr Opin Crit Care 17: 658-665.

10. Rosenthal VD, Bijie H, Maki DG, Mehta Y, Apisarnthanarak A, Medeiros EA, Leblebicioglu H, Fisher D, Álvarez-Moreno C, Khader IA, Del Rocío González Martínez M, Cuellar LE, Navoa-Ng JA, Abouqal R, Guanche Garcell H, Mitrev Z, Pirez García MC, Hamdi A, Dueñas L, Cancel E, Gurskis V, Rasslan O, Ahmed A, Kanj SS, Ugalde OC, Mapp T, Raka L, Yuet Meng C, Thu le TA, Ghazal S, Gikas A, Narváez LP, Mejía N, Hadjieva N, Gamar Elanbya MO, Guzmán Siritt ME, Jayatilleke K; INICC members (2012) International Nosocomial Control Consortium (INICC) report, data summary of 36 countries, for 2004-2009. Am J Infect Control 40: 396-407.

11. Alp E, Kiran B, Altun D, Kalin G, Coskun R, Sungur R, Akin A, Percin D, Doganay M (2011) Changing pattern of antibiotic susceptibility in intensive care units: Ten years experience of a university hospital. Anaerobe 17: 422-425.

12. Alp E, Esel D, Yildiz O, Voss A, Melchers W, Doganay M (2006) Genotypic analysis of Acinetobacter bloodstream infection isolates in a Turkish university hospital. Scand J Infect Dis 38: 335-340.

13. Alp E, Leblebicioğlu H, Doganay M, Voss A (2011) Infection control practice in countries with limited resources. Ann Clin Microbiol Antimicrob 10: 36.

14. Lynch P, Pittet D, Borg MA, Mehtar S (2007) Infection control in countries with limited resources. J Hosp Infect 65 : $148-150$. 
15. Damani N (2007) Simple measures save lives: An approach to infection control icountries with limited resources. J Hosp Infect 65: 151-154.

16. Alp E, Elmali F, Ersoy S, Kucuk C, Doganay M (2014) Incidence and risk factors of surgical site infection in general surgery in a developing country. Surg Today 44: 685-689.

17. Alp E, Altun D, Ulu-Kilic A, Elmali F (2014) What really affects surgical site infection rates in general surgery in a developing country? J Infect Public Health 7: 445-449.

18. Alp E, Güven M, Yildiz O, Aygen B, Voss A, Doganay M (2004) Incidence, risk factors and mortality of nosocomial pneumonia in intensive care units: a prospective study. Ann Clin Microbiol Antimicrob 3: 17.

19. McCorry A, Damani N, Rajendran R (2010) Reducing the use of 'high-risk' antibiotics through implementation of an antibiotic stewardship programme. Br J Clin Pharm 2: 341344.

20. Alp E, Kalin G, Coskun R, Sungur M, Guven M, Doganay M (2012) Economic burden of ventilator-associated pneumonia in a developing country. J Hosp Infect 81: 128-130.

21. Van den Broek PJ, Kluytmans JA, Ummels LC, Voss A, Vandenboucke-Grauls CM (2007) How many infection control staff do we need in hospitals? J Hosp Infect 65: 108111.

22. Alp E, Altun D, Cevahir F, Ersoy S, Cakir O, McLaws ML (2014) Evaluation of the effectiveness of an infection control program in adult intensive care units: A report from a middleincome country. Am J Infect Control 42: 1056-1061.

23. Hugonnet S, Chevrolet JC, Pittet D (2007) The effect of workload on infection risk in critically ill patients. Crit Care Med 35: 76-81.

24. Kubilay Z, Damani N, Mascarello M, Pittet D, Alegranzi B (2014) Impact of Hand Hygiene to Reduce Transmission and/or Infections by Multi-Drug Resistant Organisms in Healthcare: A Systematic Review. 54th Interscience Conference on Antimicrobial Agents and Chemotherapy (ICAAC) Congress, 5th-9th September. Washington, DC, USA. Poster No. K-1680.

25. Haagsma JA, Tariq L, Heederik DJ, Havelaar AH (2012) Infectious disease risks associated with occupational exposure: a systematic review of the literature. Occup Environ Med 69: 140-146.

26. Alp E, Cevahir F, Gökahmetoglu S, Demiraslan H, Doganay M (2012) Prevaccination screening of health-care workers for immunity to measles, rubella, mumps, and varicella in a developing country: What do we save? J Infect Public Health 5: $127-132$.

27. World Health Organization (2009) Core components for infection prevention and control programmes. Geneva: WHO. Available:

http://apps.who.int/medicinedocs/documents/s16342e/s16342 e.pdf. Accessed 15 September 2015.

28. Jaggi N, Rodrigues C, Rosenthal VD, Todi SK, Shah S, Saini N, Todi SK, Shah S, Saini N, Dwivedy A, Udwadia FE,
Mehta P, Chakravarthy M, Singh S, Sahu S, Govil D, Hegd A, Kapadia F, Bhakta A, Bhattacharyya M, Singhal T, Naik R, Kothari V, Gupta A, Shetty S, Binu S, Pinto P, Poojary A, Koppikar G, Bhandarkar L, Jadhav S, Chavan N, Bahirune S, Durgad S, Nataraj G, Surase P, Gokul BN, Sukanya R, Pushparaj L, Radhakrishnan K (2013) Impact of an International Nosocomial Infection Control Consortium multidimensional approach on central line-associated bloodstream infection rates in adult intensive care units in eight cities in India. Int J Infect Dis 17: 1218-1224.

29. Leblebicioğlu H, Yalcin AN, Rosenthal VD, Koksal I, Sirmatel F, Unal S, Koksal I, Sirmatel F, Unal S, Turgut H, Ozdemir D, Ersoz G, Uzun C, Ulusoy S, Esen S, Ulger F, Dilek A, Yilmaz H, Turhan O, Gunay N, Gumus E, Dursun O, Yýlmaz G, Kaya S, Ulusoy H, Cengiz M, Yilmaz L, Yildirim G, Topeli A, Sacar S, Sungurtekin H, Uğurcan D, Geyik MF, Şahin A, Erdogan S, Kaya A, Kuyucu N, Arda B, Bacakoglu F (2013) Effectiveness of a multidimensional approach for prevention of ventilator-associated pneumonia in 11 adult intensive care units from 10 cities of Turkey: findings of the International Nosocomial Infection Control Consortium (INICC). Infection 41: 447-456.

30. Guanche-Garcell H, Morales-Perez, Rosenthal VD (2013) Effectiveness of a multidimensional approach for the prevention of ventilator-associated pneumonia in an adult intensive care unit in Cuba: Findings of the International Nosocomial Infection Control Consortium (INICC). J Infect Public Health 6: 98-107.

31. Erdem H, Dizbay M, Karabey S, Kaya S, Demirdal T, Koksal I, Inan A, Erayman I, Ak O, Ulu-Kilic A, Karasahin O, Akbulut A, Elaldi N, Yilmaz G, Candevir A, Gul HC, Gonen I, Oncul O, Aslan T, Azak E, Tekin R, Kocak Tufan Z, Yenilmez E, Arda B, Gungor G, Cetin B, Kose S, Turan H, Akalin H, Karabay O, Dogan-Celik A, Albayrak A, Guven T, Celebi G, Ozgunes N, Ersoy Y, Sirmatel F, Oztoprak N, Balkan II, Bayazit FN, Ucmak H, Oncu S, Ozdemir D, Ozturk-Engin D, Bitirgen M, Tabak F, Akata F, Willke A, Gorenek L, Ahmed SS, Tasova Y, Ulcay A, Dayan S, Esen S, Leblebicioglu H, Altun B, Unal S (2013) Withdrawal of Staphylococcus aureus from intensive care units in Turkey. Am J Infect Control 41: 1053-1058.

\section{Corresponding author}

Emine Alp

Erciyes University, Faculty of Medicine

Department of Infectious Disease

38039, Kayseri, Turkey

Phone: +90 5363146430

Fax: + 903524375273

Email: ealp@erciyes.edu.tr

Conflict of interests: No conflict of interests is declared. 